\title{
GPS phase scintillation at high latitudes during geomagnetic storms of 7-17 March 2012 - Part 2: Interhemispheric comparison
}

\author{
P. Prikryl ${ }^{1,9}$, R. Ghoddousi-Fard ${ }^{2}$, L. Spogli ${ }^{3}$, C. N. Mitchell ${ }^{4}$, G. Li ${ }^{5}$, B. Ning ${ }^{5}$, P. J. Cilliers ${ }^{6}$, V. Sreeja ${ }^{7}$, M. Aquino ${ }^{7}$, \\ M. Terkildsen ${ }^{8}$, P. T. Jayachandran ${ }^{9}$, Y. Jiao ${ }^{10}$, Y. T. Morton ${ }^{10}$, J. M. Ruohoniemi ${ }^{11}$, E. G. Thomas ${ }^{11}$, Y. Zhang ${ }^{12}$, \\ A. T. Weatherwax ${ }^{13}$, L. Alfonsi ${ }^{3}$, G. De Franceschi ${ }^{3}$, and V. Romano ${ }^{3}$ \\ ${ }^{1}$ Geomagnetic Laboratory, Natural Resources Canada, Ottawa, ON, Canada \\ ${ }^{2}$ Canadian Geodetic Survey, Natural Resources Canada, Ottawa, ON, Canada \\ ${ }^{3}$ Istituto Nazionale di Geofisica e Vulcanologia, Rome, Italy \\ ${ }^{4}$ Department of Electronic and Electrical Engineering, University of Bath, Bath, UK \\ ${ }^{5}$ Institute of Geology and Geophysics, Chinese Academy of Sciences, Beijing, China \\ ${ }^{6}$ Space Science Directorate, South African National Space Agency, Hermanus, South Africa \\ ${ }^{7}$ Nottingham Geospatial Institute, University of Nottingham, Nottingham, UK \\ ${ }^{8}$ IPS Radio and Space Services, Bureau of Meteorology, Haymarket, NSW, Australia \\ ${ }^{9}$ Physics Department, University of New Brunswick, Fredericton, NB, Canada \\ ${ }^{10}$ Department of Electrical and Computer Engineering, Colorado State University, Fort Collins, CO, USA \\ ${ }^{11}$ Bradley Department of Electrical and Computer Engineering, Virginia Tech, Blacksburg, VA, USA \\ ${ }^{12}$ Johns Hopkins University Applied Physics Lab, Laurel, MD, USA \\ ${ }^{13}$ Department of Physics and Astronomy, Siena College, Loudonville, NY, USA \\ Correspondence to: P. Prikryl (paul.prikryl@unb.ca)
}

Received: 18 December 2014 - Revised: 1 April 2015 - Accepted: 3 April 2015 - Published: 2 June 2015

\begin{abstract}
During the ascending phase of solar cycle 24, a series of interplanetary coronal mass ejections (ICMEs) in the period 7-17 March 2012 caused geomagnetic storms that strongly affected high-latitude ionosphere in the Northern and Southern Hemisphere. GPS phase scintillation was observed at northern and southern high latitudes by arrays of GPS ionospheric scintillation and TEC monitors (GISTMs) and geodetic-quality GPS receivers sampling at $1 \mathrm{~Hz}$. Mapped as a function of magnetic latitude and magnetic local time (MLT), the scintillation was observed in the ionospheric cusp, the tongue of ionization fragmented into patches, sun-aligned arcs in the polar cap, and nightside auroral oval and subauroral latitudes. Complementing a companion paper (Prikryl et al., 2015a) that focuses on the highlatitude ionospheric response to variable solar wind in the North American sector, interhemispheric comparison reveals commonalities as well as differences and asymmetries between the northern and southern high latitudes, as a consequence of the coupling between the solar wind and magnetosphere. The interhemispheric asymmetries are caused by the
\end{abstract}

dawn-dusk component of the interplanetary magnetic field controlling the MLT of the cusp entry of the storm-enhanced density plasma into the polar cap and the orientation relative to the noon-midnight meridian of the tongue of ionization.

Keywords. Ionosphere (ionospheric disturbances; ionospheric irregularities; polar ionosphere)

\section{Introduction}

The scintillation of the global navigation satellite system (GNSS) radio signal is caused by refraction and diffraction of radio waves passing through ionospheric irregularities on scales from tens of meters to a few kilometers including steep electron density gradients (Basu et al., 1998; Kintner et al., 2007). Variable ionospheric electron density causes variable group delay and phase advance of the radio wave, resulting in rapid phase fluctuations or phase scintillation. Diffraction of a plane wave passing through an irregular ionosphere results in constructive or destructive interference across a spatially 
irregular wavefront, leading to fluctuations in signal intensity or amplitude scintillation. Both effects can cause errors in receiver signal tracking loops and, in some cases, a loss of signal lock that can lead to navigational errors (Kintner et al., 2007).

Ionospheric irregularities are produced through the coupling of solar wind to the magnetosphere-ionosphere system, resulting in high-latitude phenomena that include fieldaligned currents (FACs), auroral electrojets, energetic particle precipitation, ionospheric convection, subauroral polarization streams (SAPS), storm-enhanced density (SED), tongues of ionization (TOI) and patches of enhanced plasma density convecting in the polar cap. These phenomena occur, sometimes simultaneously, in both hemispheres, threaded by magnetic field lines that are either closed or open, i.e., connected to the interplanetary magnetic field (IMF). The driving mechanism for these processes is the magnetic reconnection between the IMF and the Earth's magnetic field (Dungey, 1961; Echer et al., 2008) that controls energy and momentum transfer in the magnetosphere in both the Northern and Southern Hemisphere. Most prominently, conjugate auroras display similarities as well as asymmetries between hemispheres (DeWitt, 1962; Sato et al., 1998, 2005; Østgaard et al., 2003, 2004; Laundal and Østgaard, 2009). Also, interhemispheric similarities and asymmetries are manifested by the ionospheric convection at high latitudes (Cowley et al., 1991; Ruohoniemi and Baker, 1998; Milan et al., 2001; Kozlovsky et al., 2003, Nishitani et al., 2003), including SAPS (Kunduri et al., 2012; Kunduri, 2013). The seasonal dependence of interhemispheric asymmetries of FAC patterns has been observed (Papitashvilli et al., 2002). The most prominent interhemispheric asymmetry in the polar ionosphere on open magnetic field lines is caused by the IMF $B_{y}$. The tension on the newly opened field lines that has a net east-west component, if IMF is non zero, is opposite in the Northern and Southern Hemisphere (Cowley, 1981; Tsurutani et al., 1984). As a result, the ionospheric convection in the polar cap is oppositely tilted with respect to the noon-midnight meridian and thus causes the opposite tilt of TOI in the Northern and Southern Hemisphere. Also, noon-midnight asymmetry of auroral activity is observed during intervals of large IMF $B_{y}$ (Akasofu and Tsurutani, 1984).

The occurrence of GNSS scintillation in both hemispheres is a function of magnetic local time and geomagnetic latitude (Spogli et al., 2009; Li et al., 2010; Alfonsi et al., 2011; Prikryl et al., 2011a). The phase scintillation is often collocated with bright auroras (Smith et al., 2008 Kinrade et al., 2013), fast-drifting irregularities and steep density gradients in the cusp (Prikryl et al., 2011a), and TOI and patches in the polar cap; more recently, weak to moderate scintillation was observed collocated with SAPS at subauroral latitudes (Prikryl et al., 2013b, 2015b). Interhemispheric comparison of high-latitude ionospheric scintillation during geomagnetic storms has revealed similarities as well as asymmetries between the northern and southern auroral zones, cusps and po- lar caps (Prikryl et al., 2011b, Kinrade et al., 2012; Prikryl et al., 2013a).

The interval of geomagnetic storms of 7-17 March 2012 was selected at the Climate and Weather of the Sun-Earth System (CAWSES) II Workshop for group study of space weather effects during the ascending phase of solar cycle 24 (Tsurutani et al., 2014). With a focus on the North American sector, the companion paper (Prikryl et al., 2015a) studies high-latitude ionospheric response to a series of storms including GPS scintillation. To complement the latter study, the present paper includes the GPS phase scintillation observed in the European sector and Antarctica and focuses on the interhemispheric comparison of GPS phase scintillation response at high latitudes.

\section{Instruments and data}

The Canadian High Arctic Ionospheric Network (CHAIN) (Jayachandran et al., 2009), which consists of GPS ionospheric scintillation and TEC monitors (GISTMs), is described in the companion paper. CHAIN data are supplemented by scintillation data from the same type of receiver operated in Gakona, Alaska (Jiao et al., 2013). GISTMs have been operated in the European sector in Scandinavia and in southern high latitudes, primarily in Antarctica (De Franceschi et al., 2006; Li et al., 2010; Ngwira et al., 2010; Prikryl et al., 2011b, their Table 1). South Pole GPS receiver operations are a collaborative effort of University of Bath and Siena College. The GISTMs of the South African National Antarctic Expedition (SANAE) in Antarctica are operated by the Space Science Directorate of the South African Space Science Directorate (SANSA). The array of GISTMs is complemented by geodetic-quality GPS receivers sampling at $1 \mathrm{~Hz}$ to compute proxy indices (mean delta phase rate, mDPR, and standard deviation of delta phase rate, sDPR) (Ghoddousi-Fard et al., 2013). Most of the $1 \mathrm{~Hz}$ GNSS data are obtained from the NASA's Crustal Dynamics Data Information System (http://cddis.gsfc.nasa.gov/gnss/). Figure 1a and $b$ show locations of GISTMs (red dots) and the $1 \mathrm{~Hz}$ GPS receivers (black dots) in the northern and southern high latitudes. Also, the conjugate locations of GISTMs in the opposite hemisphere are shown (blue dots).

The Special Sensor Ultraviolet Scanning Imager (SSUSI) is onboard the Defense Meteorological Satellite Program (DMSP) satellites (F16 to F18). It measures auroral and airglow emissions in far-ultraviolet (FUV) bands, and provides partial global auroral images in five "colors": $121.6 \mathrm{~nm}$ (proton aurora), $130.4 \mathrm{~nm}$ (O emission), $135.6 \mathrm{~nm}$ (O emission), 140 to $150 \mathrm{~nm}$ (Lyman-Birge-Hopfield (LBH)S: N2 LBH short band) and 165 to $180 \mathrm{~nm}$ (LBHL: N2 LBH long band) (Paxton et al., 2002). The LBHS and LBHL bands were used to derive the energy flux and mean energy of precipitating electrons in the auroral oval (Zhang and Paxton, 2008, and references therein). SSUSI takes 15 auroral images in both 


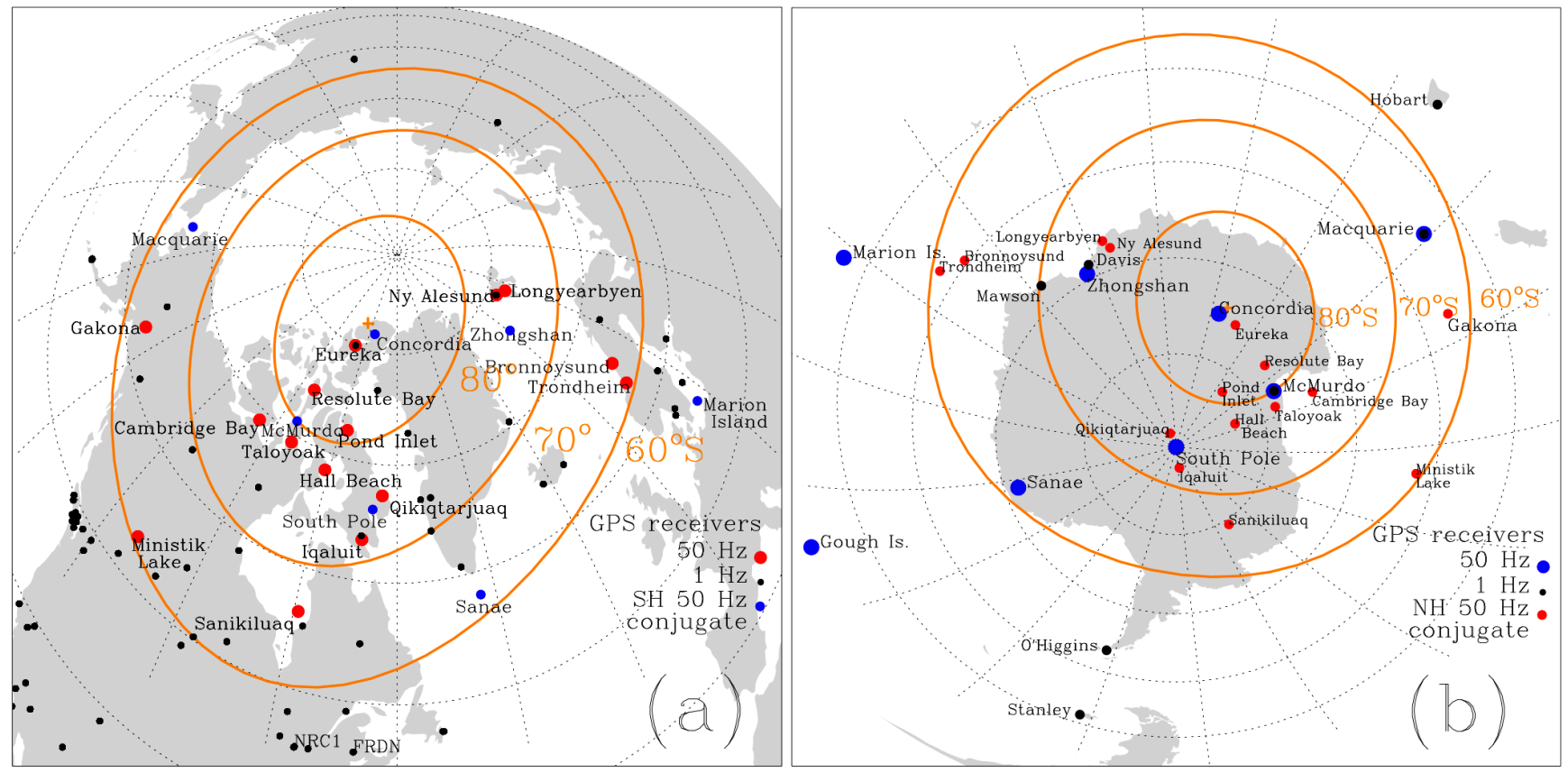

Figure 1. The GISTM arrays complemented by geodetic-quality $1 \mathrm{~Hz}$ GPS receivers (black dots) in the (a) northern and (b) southern high latitudes. The northern GISTMs (red dots) and southern GISTMs (blue dots) are also shown at their conjugate locations in the opposite hemispheres. The altitude-adjusted corrected geomagnetic (AACGM) latitudes 60,70 and $80^{\circ}$, in yellow, are superposed over the geographic grid.

hemispheres every day, and the images have a spatial resolution down to $10 \mathrm{~km}$ at nadir. The presented SSUSI auroral images have been re-binned with a grid side of $25 \mathrm{~km} \times 25 \mathrm{~km}$. The SSUSI is almost the same as a global ultraviolet imager (see Zhang and Paxton, 2008).

The Super Dual Auroral Radar Network (SuperDARN) is a network of coherent-backscatter HF radars with a collective field of view that covers a large fraction of the highlatitude ionosphere (Greenwald et al., 1995; Chisham et al., 2007). The radars transmitting at frequencies $8-20 \mathrm{MHz}$ receive backscatter returns from field-aligned ionospheric plasma irregularities to measure the line-of-sight Doppler velocity, spectral width and backscatter power. These measurements are used to infer convection and electrostatic potential patterns in the high-latitude ionosphere (Ruohoniemi and Baker, 1998; Shepherd and Ruohoniemi, 2000). The GPS TEC maps are obtained using the plotting tools (Thomas et al., 2013) available online (http://vt.superdarn.org), with the TEC data downloaded from the Madrigal database (http: //madrigal.haystack.mit.edu/madrigal/). The TEC data were processed using the MIT Automated Processing of GPS (MAPGPS) software, which allows the processing of GPS data into global TEC maps (Rideout and Coster, 2006).

Solar wind data were obtained from the Goddard Space Flight Center Space Physics Data Facility CDAWeb and OMNIWeb data sets (King and Papitashvili, 2005). The OMNIWeb data set of interplanetary magnetic field and solar wind plasma parameters have combined the data from available solar wind monitors, primarily from Advanced Composition Explorer (ACE). The OMNIWeb data set propagates the solar wind measurements to the nose of the Earth's bow shock to accommodate for propagation delays from the spacecraft. The OMNIWeb data set also provides geomagnetic indices including AE and SYM-H (World Data Center, Kyoto Japan; http://wdc.kugi.kyoto-u.ac.jp/).

\section{Summary of the phase scintillation occurrence in the Southern Hemisphere during the 6-17 March 2012 interval}

A summary (Fig. 2) of the OMNI data set shows 5 min averages of the solar wind velocity, $V_{\mathrm{sw}}$; the IMF components $B_{y}$ and $B_{z}$; total magnitude, $B$; and proton density, $n_{\mathrm{p}}$; as well as the provisional geomagnetic indices AE and SYMH. Five upstream interplanetary shocks are indicated by vertical dotted lines (Tsurutani et al., 2014). Four storms that are discussed in the companion paper are characterized by deep depressions in the storm index SYM-H (Fig. 2g). The hourly occurrence of phase scintillation at Concordia (DMC), South Pole (SPO) and SANAE (SNA) are shown (Fig. 2f). As shown in the companion paper for the northern high latitudes, enhancements in scintillation occurrence followed the arrivals of shocks and onsets of geomagnetic storms. 


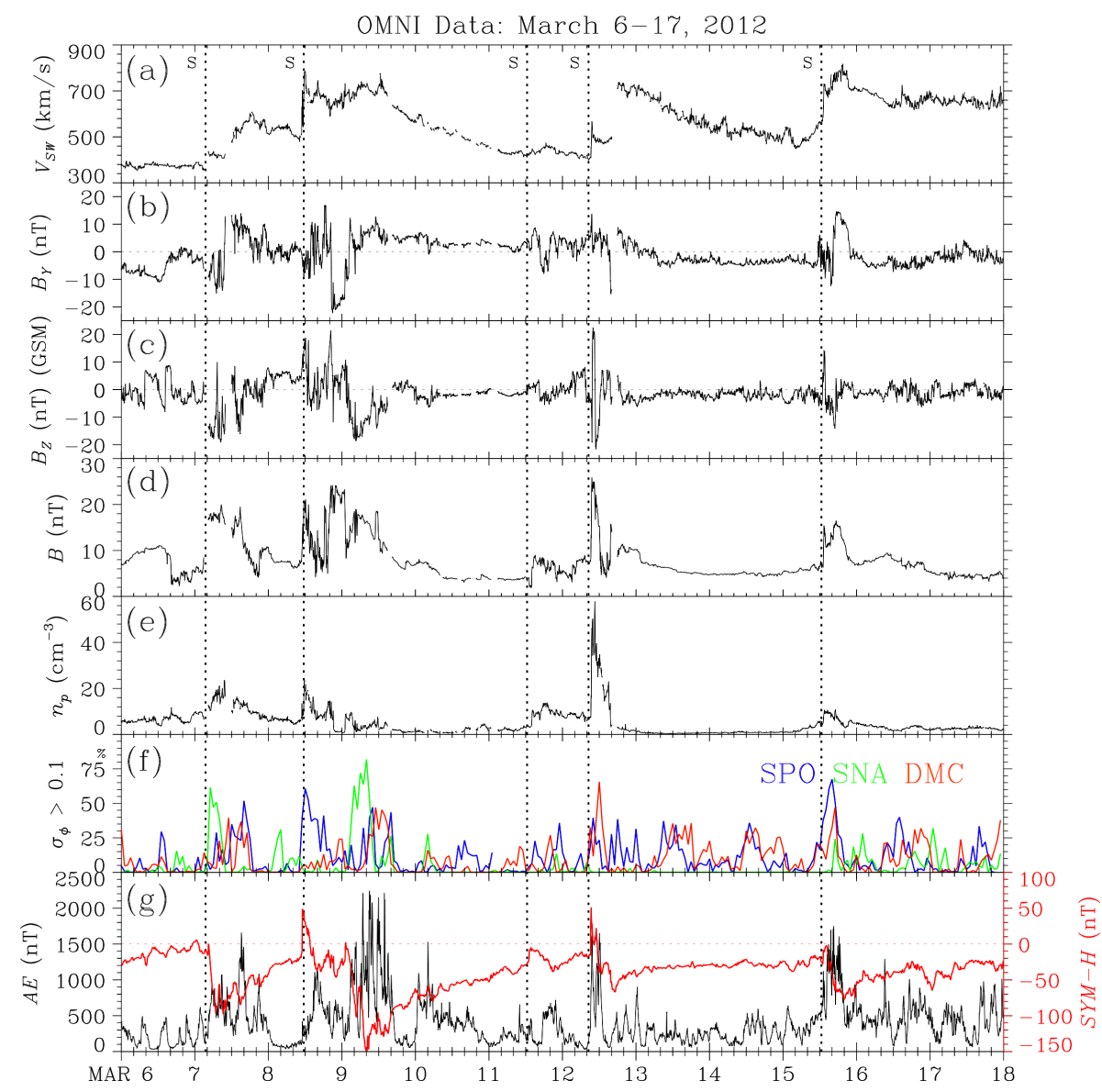

Figure 2. The interplanetary data from the $5 \mathrm{~min}$ OMNI data set. The hourly occurrences of phase scintillation $\left(\sigma_{\Phi}>0.1 \mathrm{rad}\right)$ observed at South Pole (SPO), Concordia (DMC) and SANAE (SNA), and provisional geomagnetic indices AE and SYM-H are shown in the bottom two panels.

The Southern Hemisphere high-latitude maps of phase scintillation exceeding $\sigma_{\Phi}>0.1 \mathrm{rad}$ and $\mathrm{sDPR}>2 \mathrm{~mm} \mathrm{~s}^{-1}$ as a function of altitude-adjusted corrected geomagnetic (AACGM) latitude (Baker and Wing, 1989; Shepherd, 2014) and time during the same period of geomagnetic storms of March 2012 are shown in Figs. 3 and 4. The scintillation is mapped using grid cells of $1^{\circ} \times 1 \mathrm{~h}$ in size and assuming the ionospheric pierce point (IPP) height at $350 \mathrm{~km}$. To minimize the multipath effect, only GPS satellites with elevation angles exceeding $30^{\circ}$ are used. The values of $\sigma_{\Phi}$ and sDPR are projected to the vertical to account for geometrical effects on the measurements made at different elevation angles. A summary of scintillation occurrence for the North American sector is provided in the companion paper (Prikryl et al., 2015a, their Figs. 3 and 4).

The scintillation occurrence mapped as a function of universal time (UT) shows the response to arrivals of upstream interplanetary shocks (Tsurutani et al., 2014) that are indicated by vertical dotted lines (Figs. 3a, b, 4a, b). A panel showing provisional geomagnetic indices AE and SYM-H is inserted for convenience of comparison. The onsets of scin- tillation events in Antarctica closely followed the arrival of each upstream interplanetary shock. In each case, the enhanced scintillation region expanded equatorward to low auroral and subauroral latitudes as demonstrated by both $\sigma_{\Phi}$ and sDPR. The highest scintillation occurrence and its equatorward expansion coincided with the main phase of geomagnetic storms (Gonzales et al., 1994) that are indicated by depressions in the SYM-H index. Solar wind data are shown in Fig. 2a-e.

Figures $3 \mathrm{c}, \mathrm{d}$ and $4 \mathrm{c}, \mathrm{d}$ show the scintillation occurrence as a function of the AACGM latitude and magnetic local time (MLT) for each day. The positions of the statistical auroral oval (Feldstein and Starkov, 1967; Holzworth and Meng, 1975) for conditions approximately proportional to the Kp index are superposed in white solid lines. The control parameter for the Feldstein model is the index Q (IQ) ranging from 0 to 6 for quiet to active oval. This mapping is used to identify regions of enhanced scintillation occurrence in the context of the coupling processes between the solar wind and magnetosphere. The phase scintillation occurrence is routinely observed in the cusp, from where the enhanced 

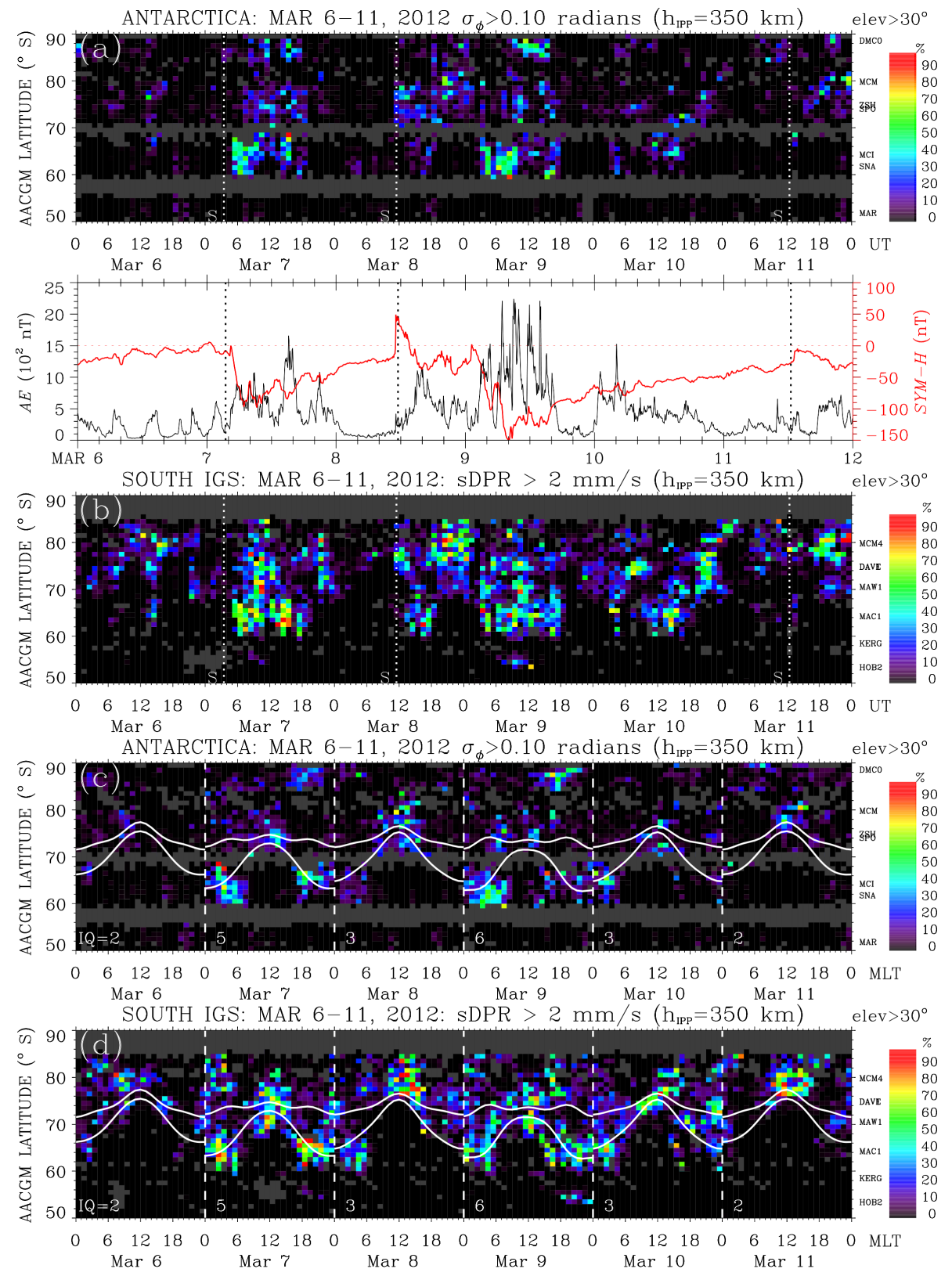

Figure 3. The occurrence of phase scintillation $\left(\sigma_{\Phi}>0.1 \mathrm{rad}\right.$ and sDPR $\left.>2 \mathrm{~mm} \mathrm{~s}^{-1}\right)$ as a function of AACGM latitude and (a, b) UT or (c, d) MLT in the Southern Hemisphere from 6 to 11 March. The dotted vertical lines in the top two panels indicate interplanetary shock arrival times. The dashed vertical lines separate days mapped in MLT. The IQ values of the statistical auroral oval are chosen to be approximately proportional to maximum 3-hourly Kp index. A panel showing provisional geomagnetic indices AE and SYM-H is inserted for convenience of comparison.

scintillation often extends into a band in the polar cap and is collocated with a TOI fragmented into patches. In the Southern Hemisphere, the scintillation band in the polar cap is tilted toward dusk when the IMF $B_{y}$ is duskward $\left(B_{y}>0\right)$ or toward dawn when the IMF $B_{y}$ is dawnward $\left(B_{y}<0\right)$. This is just the opposite in the Northern Hemisphere, as further discussed in Sect. 4. For example, on 13, 14 and 16 March, when the IMF was predominantly dawnward $\left(B_{y}<0\right)$, scintillation bands were tilted dawnward in the Southern Hemisphere, while they were tilted duskward in the Northern Hemisphere (Prikryl et al., 2015a, their Fig. 4b and c). On 15 March, when the IMF $B_{y}$ switched polarity and was oriented duskward $\left(B_{y}>0\right)$, the scintillation band on average tilted dawnward in the Northern Hemisphere and duskward in the Southern Hemisphere. 

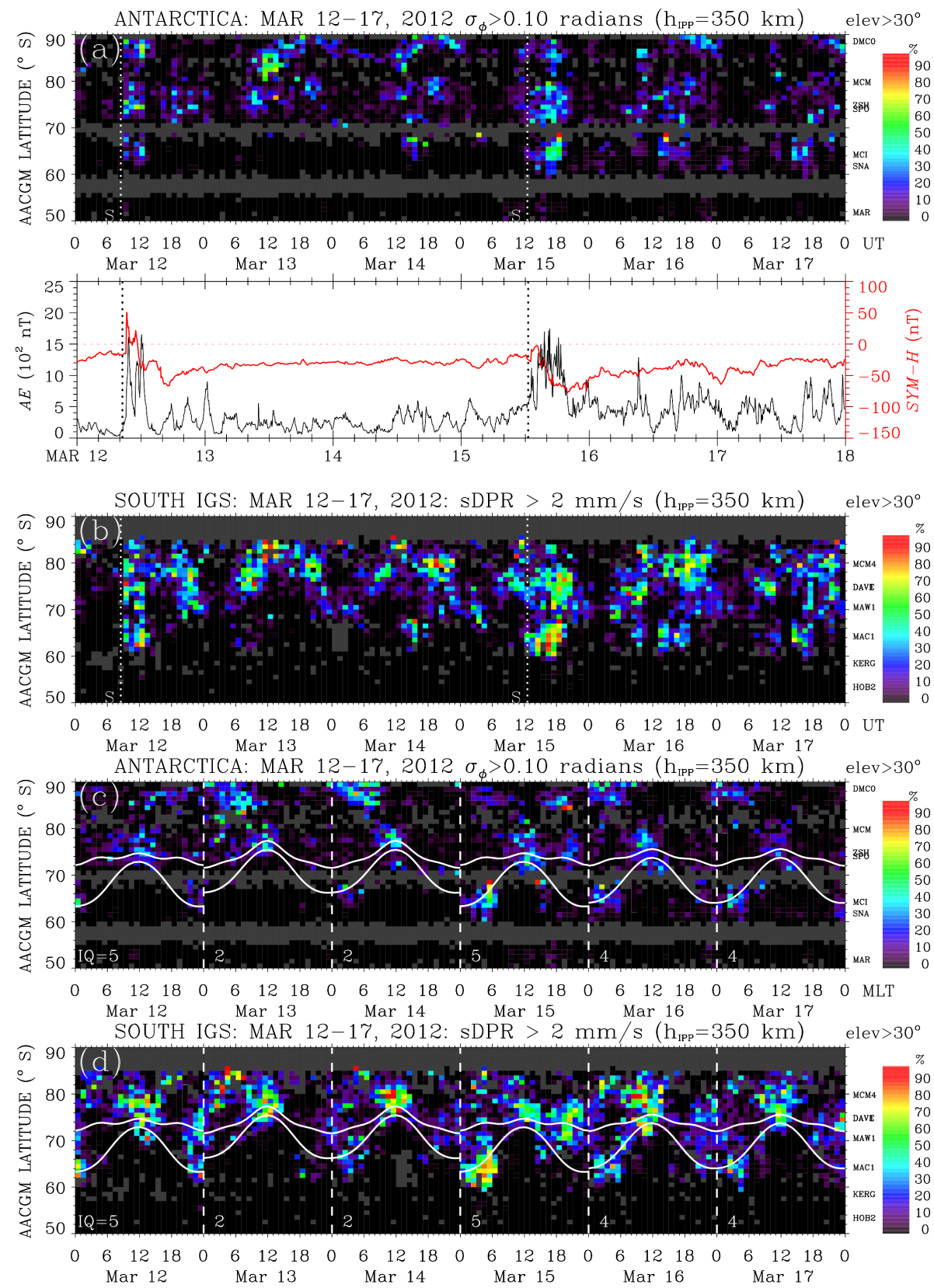

Figure 4. Same as Fig. 3 but for the interval from 12 to 17 March.

Enhanced scintillation $\left(\sigma_{\Phi}>0.1 \mathrm{rad}\right.$ or SDPR $\left.>2 \mathrm{~mm} \mathrm{~s}^{-1}\right)$ also occurred in the southern auroral and subauroral latitudes during the most disturbed days, particularly on 7, 9 and 15 March (Fig. 4c and d). Although there were gaps in the GISTM coverage at the southern auroral and subauroral latitudes, cases of weak to moderate scintillation with sDPR reaching up to about $10 \mathrm{~mm} \mathrm{~s}^{-1}$ were observed by the IGS GPS receiver in Hobart, Tasmania, on the most disturbed days of 7 and 9 March between 06:00 and 12:00 UT (Fig. 3b).

\section{Interhemispheric comparison of GPS phase scintillation occurrence}

To compare the phase scintillation in the Northern and Southern Hemisphere for selected days, the scintillation occurrence is mapped in polar coordinates on the AACGM latitude-MLT grid of $1^{\circ} \times 0.25 \mathrm{~h}$, oriented with magnetic noon at the top. Figure 5 shows the phase scintillation occurrence $\left(\sigma_{\Phi}>0.1 \mathrm{rad}\right.$ and sDPR $\left.>2 \mathrm{~mm} \mathrm{~s}^{-1}\right)$ in the northern (Fig. 5a and b) and southern (Fig. 5c and d) high latitudes on 7 March. Better coverage by GPS receivers in the Northern 

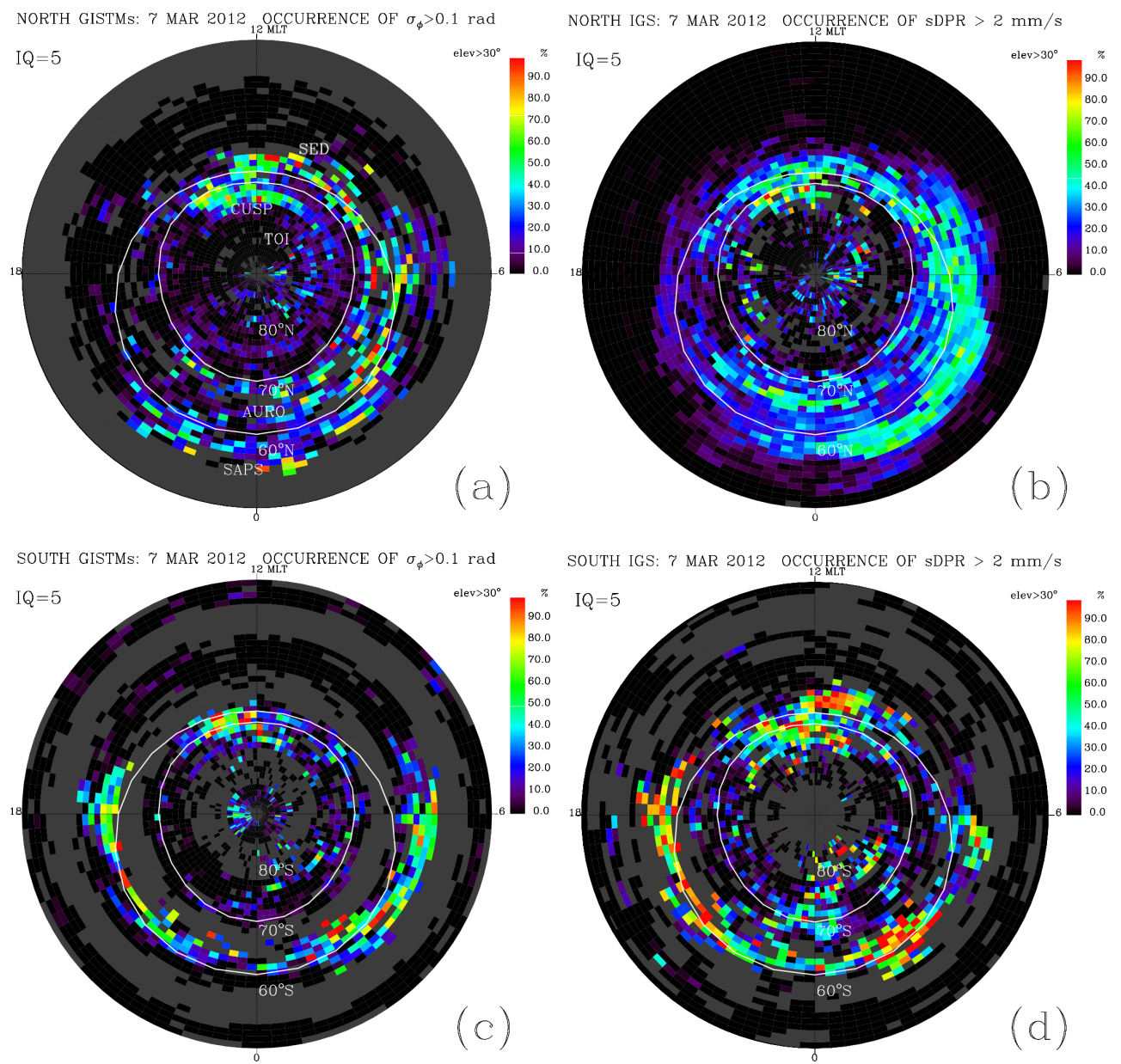

Figure 5. The phase scintillation occurrence of $(\mathbf{a}, \mathbf{c}) \sigma_{\Phi}>0.1 \mathrm{rad}$ and $\left.\mathbf{( b ,}, \mathbf{d}\right) \mathrm{sDPR}>2 \mathrm{~mm} \mathrm{~s}^{-1}$ in the coordinates of AACGM latitude vs. MLT for the northern (top panels) and southern (bottom panels) high latitudes on 7 March. The position of the statistical auroral oval (Feldstein and Starkov, 1967; Holzworth and Meng, 1975) for disturbed conditions (IQ=5) is superposed. Five regions of scintillation ("CUSP", "TOI", "AURO", "SAPS" and "SED”) are approximately indicated in the first panel.

Hemisphere makes it possible to identify the main regions of enhanced scintillation in the context of the coupling between the solar wind and magnetosphere. The scintillation regions indicated by labels in Fig. 5a are the cusp, the TOI in the polar cap, and the nightside auroral oval and sub-auroral scintillation regions. The latter may be collocated with SAPS in the midnight sector and storm-enhanced densities (SEDs) on the dayside (Foster, 1993; Foster and Burke, 2002; Foster et al., 2004, 2005; Clausen et al., 2012; Kunduri et al., 2012). The phase scintillation observed by GISTMs and $1 \mathrm{~Hz}$ GPS receivers occurs in these generic regions. Because of the dynamics of the high-latitude ionosphere, the actual location of these regions varies (e.g., the auroral oval expands and contracts depending on the instantaneous drivers in the solar wind) and daily composite maps (Fig. 5a and b) can only show their approximate mean locations. While a continuous coverage in AACGM latitude and MLT is lacking in general, the $1 \mathrm{~Hz}$ GPS receivers provide nearly continuous coverage at auroral and subauroral latitudes in the Northern Hemisphere. Although there is much less coverage by either GISTMs or $1 \mathrm{~Hz}$ GPS receivers in the Southern Hemisphere (Fig. 5c and d), similarities or differences in comparison with the Northern Hemisphere maps (Fig. 5a and b) can be examined.

Because $\sigma_{\Phi}$ and SDPR are correlated (Ghoddousi-Fard et al., 2013) and the threshold values used here are comparable, we combined the two occurrence maps into one by considering sDPR $>2 \mathrm{~mm} \mathrm{~s}^{-1}$ and $\sigma_{\Phi}>0.1 \mathrm{rad}$ to improve the coverage in magnetic latitude and MLT. The composite maps (e.g., Fig. 6a) combine $\sigma_{\Phi}$ and sDPR data (e.g., Fig. 5a and b). The scintillation occurrence is defined as $100 \times N\left(\sigma_{\Phi}>0.1\right.$ or sDPR $>2) / N_{\text {tot }}$, where $N$ is the number of cases in which the phase scintillation index exceeded given thresholds and $N_{\text {tot }}$ is the total number data points with IPPs in the bin including both GISTMs and $1 \mathrm{~Hz}$ GPS receivers. The maps for the Northern and Southern Hemisphere on 7, 12, 15 and 

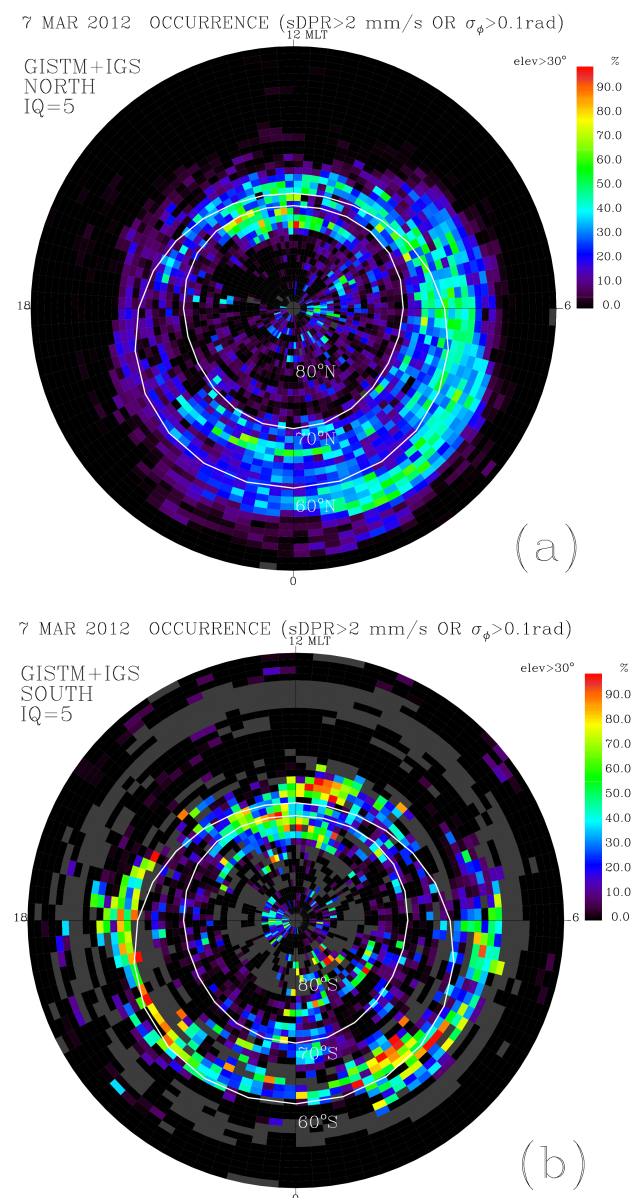

Figure 6. The composite maps of phase scintillation combining the occurrence of sDPR $>2 \mathrm{~mm} \mathrm{~s}^{-1}$ and $\sigma_{\Phi}>0.1 \mathrm{rad}$ in the (a) northern and (b) southern high latitudes on 7 March.

16 March are shown in Figs. 6-9, respectively. By merging the above-threshold occurrence of $\sigma_{\Phi}$ and sDPR into a single map, similarities and certain asymmetries in each hemisphere are revealed. The most prominent asymmetry that can be attributed to the dawn-dusk IMF component $\left(B_{y}>0\right.$ or $\left.B_{y}<0\right)$ is demonstrated by the orientation of scintillation band in the polar cap, which is opposite in the opposite hemispheres as already discussed in Sect. 3 .

On 7 March, the IMF $B_{y}$ was initially dawnward $\left(B_{y}<0\right)$ until about 10:00 UT, when it turned strongly duskward $\left(B_{y}>0\right)$ (Fig. 2b). It is the latter condition that is best represented in the composite maps of scintillation occurrence (Fig. 6). In the Northern Hemisphere (Fig. 6a) for IMF $B_{y}>0$, the TOI is drawn through the cusp in the post-noon sector by the dawnward and anti-sunward convection (see Milan et al., 2000, their Fig. 4) into the central polar cap. The dayside scintillation region in the Northern Hemisphere extends dawnward from the cusp in the post-noon sector and then poleward, as a result of the anti-sunward return flow. In the polar cap the scintillation band is generally oriented to-
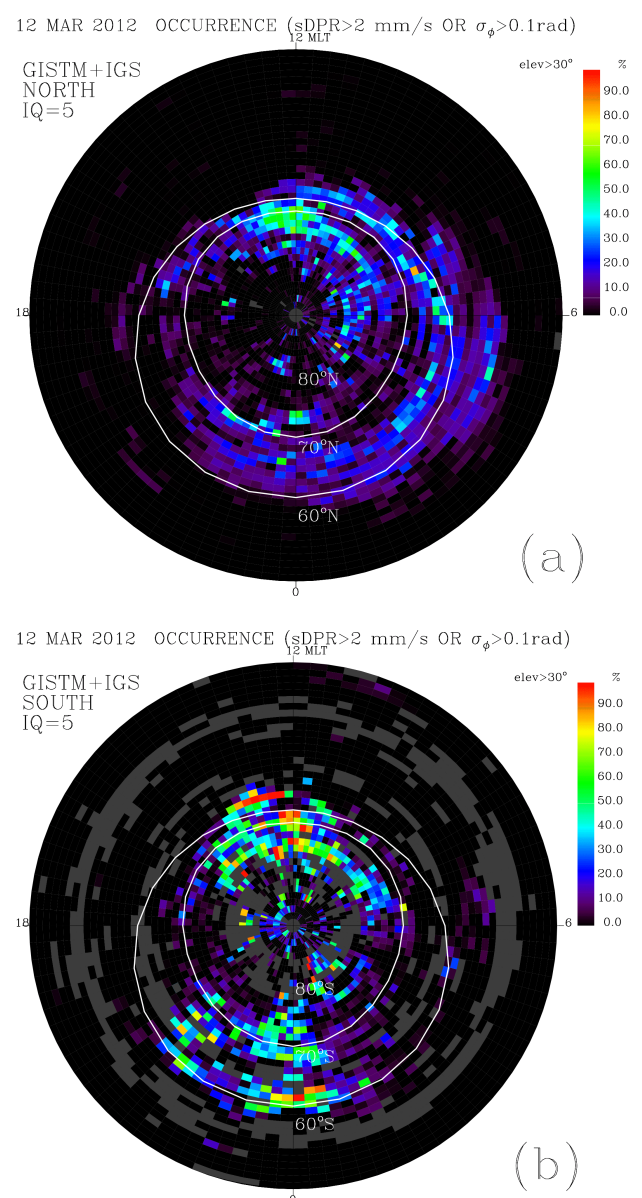

Figure 7. The composite maps of phase scintillation combining the occurrence of sDPR $>2 \mathrm{~mm} \mathrm{~s}^{-1}$ and $\sigma_{\Phi}>0.1 \mathrm{rad}$ in the (a) northern and (b) southern high latitudes on 12 March.

wards the pre-midnight sector. In the Southern Hemisphere (Fig. 6b) for IMF $B_{y}>0$, the dayside scintillation extends duskward from the pre-noon cusp and, barring some gaps, stretches poleward and towards the post-midnight sector. This was similar on 12 and 15 March (Figs. 7 and 8), again under control of predominantly duskward IMF $B_{y}>0$. On 15 March, after the shock arrival at $\sim 12: 00$ UT, the IMF fluctuated and then turned strongly duskward $\left(B_{y}>0\right)$ at about 16:00 UT. On the other hand, on March 16, the IMF $B_{y}$ was consistently dawnward $\left(B_{y}<0\right)$ throughout $24 \mathrm{~h}$, which is reflected in the location and orientation of the TOI scintillation band that is opposite in the opposite hemispheres (Fig. 9). In the Northern Hemisphere the TOI scintillation region extends duskward from the pre-noon cusp and then anti-sunward on the dusk side around the magnetic pole (Fig. 9a). In the Southern Hemisphere, the TOI extends dawnward from the post-noon cusp and then anti-sunward on the dawn side toward the magnetic pole (Fig. 9b). Some of the scintillation at the lowest latitudes on the dayside may be collocated with the SED poleward edge (see Prikryl et al., 2015a, their 

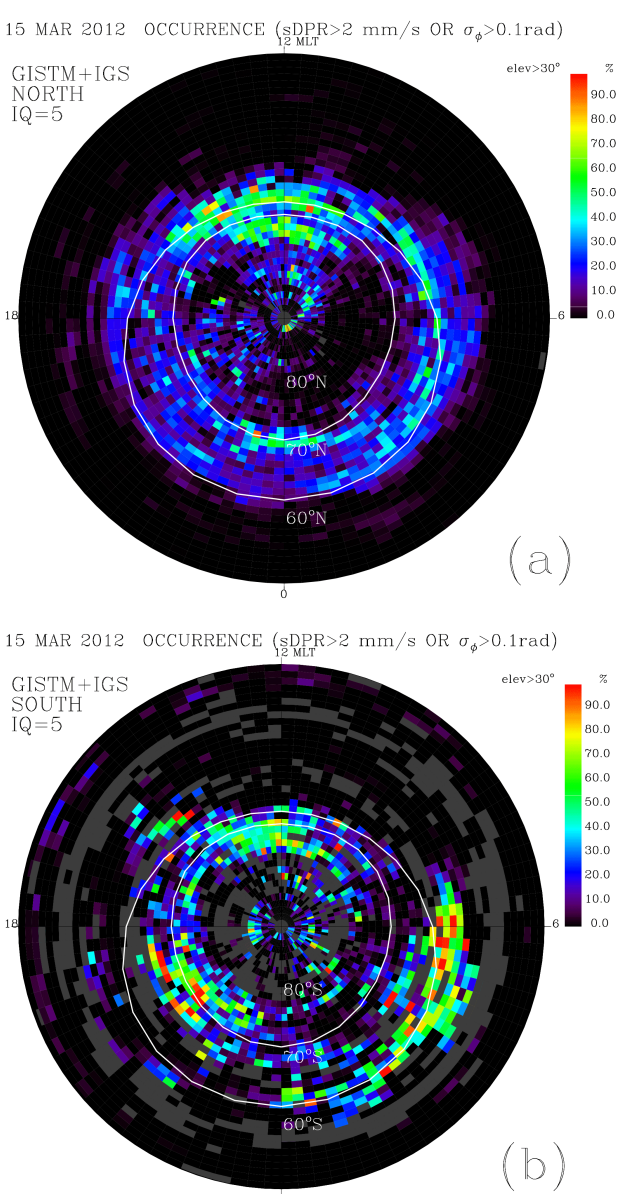

Figure 8. The composite maps of phase scintillation combining the occurrence of sDPR $>2 \mathrm{~mm} \mathrm{~s}^{-1}$ and $\sigma_{\Phi}>0.1 \mathrm{rad}$ in the (a) northern and (b) southern high latitudes on 15 March.

Fig. 15c). An asymmetry is observed between the Northern and Southern Hemisphere (Fig. 9a and b). The scintillation region equatorward of the cusp and statistical dayside auroral oval, which we associated with SED (Fig. 5a), is observed in the post-noon and pre-noon sectors in the Northern and Southern Hemisphere, respectively. This is consistent with the forming of TOI because the high density plasma is drawn into the polar cap through the cusp from the SED region, although a significant expansion of the auroral oval could render these scintillation regions parts of the dayside portion of dusk or dawn convection cells.

Figure 10a and $\mathrm{b}$ show examples of the SuperDARN convection maps in the Northern and Southern Hemisphere on 7 March at 08:00 UT, when the IMF was strongly southward with a dawnward $\left(B_{y}<0\right)$ component. The maps show an expanded convection pattern with the Heppner-Maynard (HM) boundary (Imber et al., 2013) moving to 50 AACGM latitude. The scintillation was collocated with the convection near $60^{\circ}$ magnetic latitude in the pre-midnight and postmidnight sectors. Further equatorward, near $55^{\circ}$ magnetic
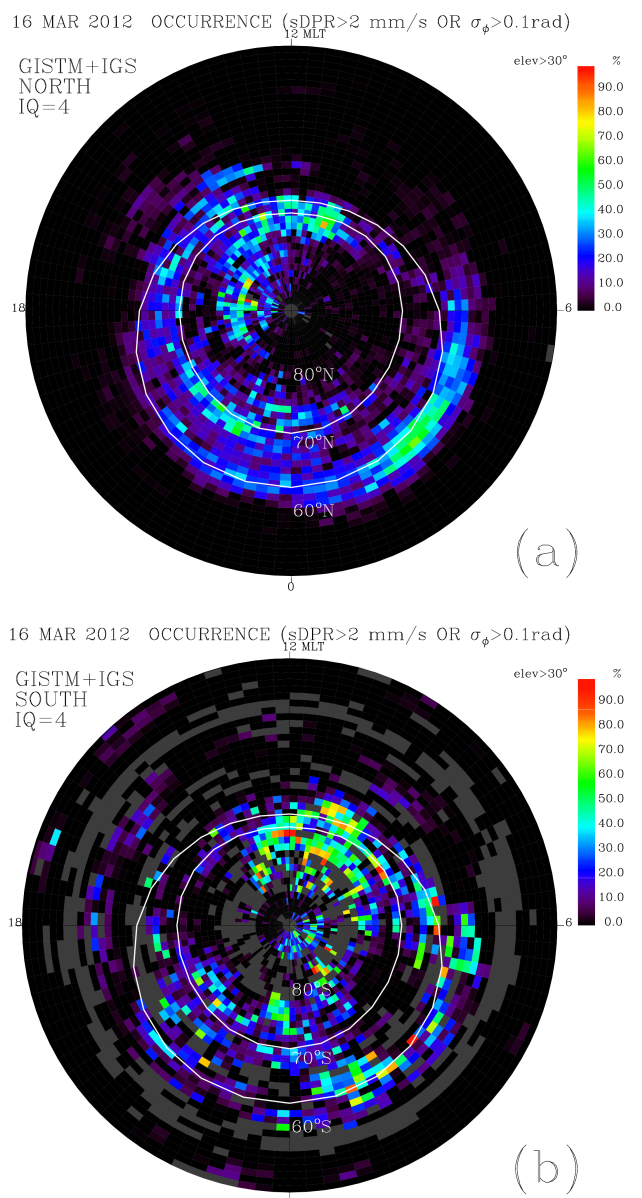

Figure 9. The composite maps of phase scintillation combining the occurrence of sDPR $>2 \mathrm{~mm} \mathrm{~s}^{-1}$ and $\sigma_{\Phi}>0.1 \mathrm{rad}$ in the (a) northern and (b) southern high latitudes on 16 March.

latitude at $\sim 23: 00$ MLT, the scintillation was closely collocated with a strong and narrow westward convection that was likely due to SAPS (further discussed below). In the central polar cap the scintillation mapped to a region of strong anti-sunward convection. On the dayside, scintillation IPPs mapped to the cusp and to the dawn convection cell. In spite of rather limited coverage by GPS/GISTMs and SuperDARN radars in the Southern Hemisphere, a few scintillation IPPs were collocated with a strong anti-sunward convection in the central polar cap and mapped to a mesoscale vortex in the cusp region.

Figure 11a and $\mathrm{b}$ show the 5 min TEC maps overlaid with the electrostatic potential contours and IPPs. In both hemispheres, the scintillation occurred in regions of enhanced TEC in the central polar cap and on the dayside in the cusp. In the Northern Hemisphere, the bulk of scintillation was collocated with the enhanced TEC in the auroral oval and mapped to the poleward edge of TEC trough. SAPS were likely present as suggested by the convection enhancement at 23:00 MLT near $55^{\circ}$ of AACGM latitude (Fig. 10a). Dur- 

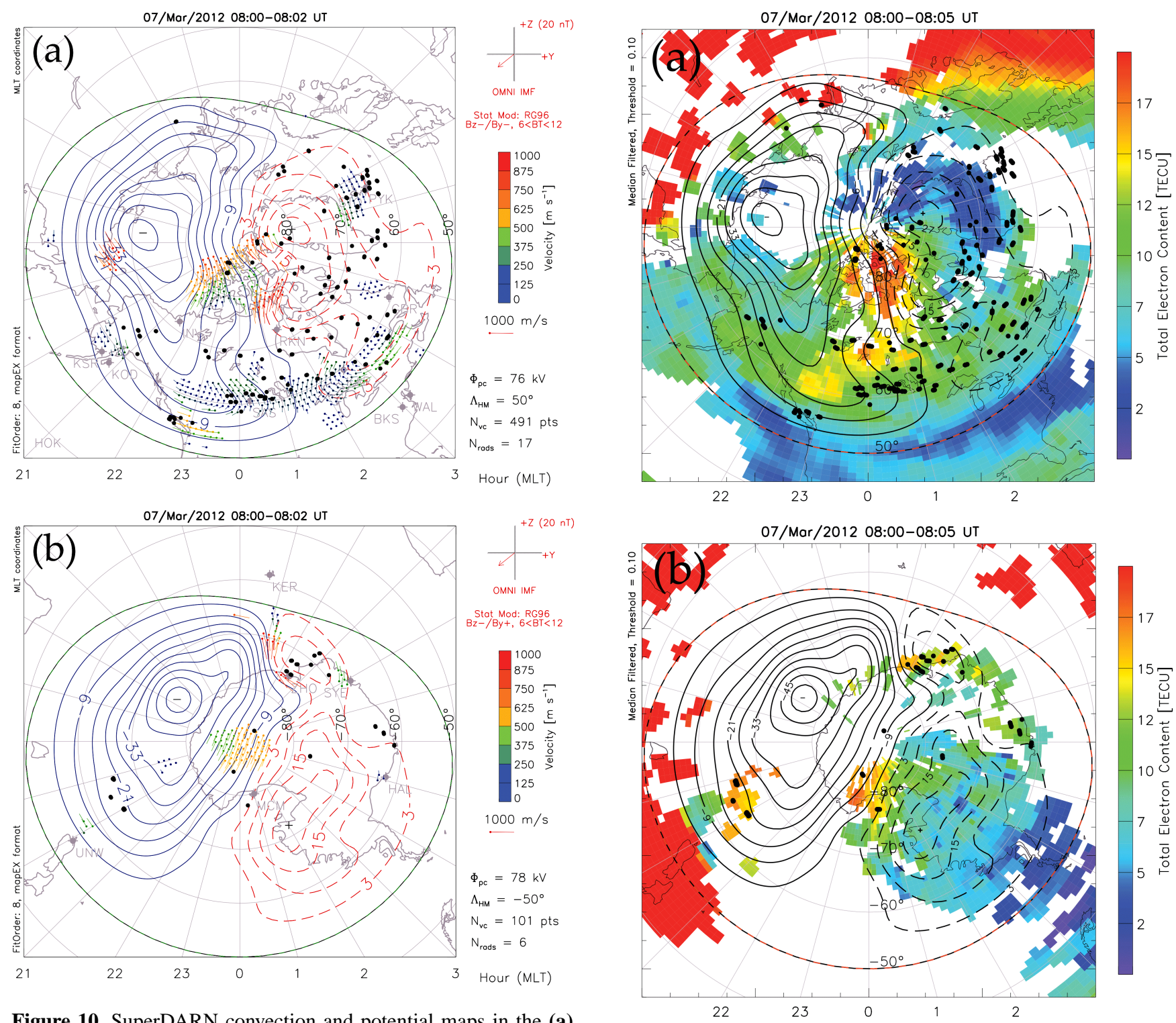

Figure 10. SuperDARN convection and potential maps in the (a) Northern and (b) Southern Hemisphere on 7 March. The IPPs with $\sigma_{\Phi}>0.1 \mathrm{rad}$ or SDPR $>2 \mathrm{~mm} \mathrm{~s}^{-1}$ are superposed as black dots.

ing another event, SAPS dynamics were observed by the SuperDARN CVW radar and GPS receivers at 30-60 s resolution (Makarevich and Bristow, 2014). The SAPS revealed a complex pattern of large- and small-scale disturbances, including a strong and narrow feature of the subauroral ion drift (SAID) collocated with a TEC enhancement poleward of TEC trough. The narrow convection feature that was collocated with scintillation (Fig. 10a) mapped to the poleward edge of the TEC trough (Fig. 11a), similar to SAID observed by Makarevich and Bristow. In the latter case, scintillation with sDPR up to $5 \mathrm{~mm} \mathrm{~s}^{-1}$ was observed by GPS receivers on the west coast of Canada and the USA (Prikryl et al., 2015b).

Figure 11. The 5 min median-filtered TEC mapped in coordinates of AACGM latitude and MLT in the (a) Northern and (b) Southern Hemisphere on 7 March between 08:00 and 08:05 UT. The TEC map is overlaid with the SuperDARN potential map and IPPs (black dots) for $\sigma_{\Phi}>0.1 \mathrm{rad}$ or sDPR $>2 \mathrm{~mm} \mathrm{~s}^{-1}$.

The Southern Hemisphere TEC map (Fig. 11b) shows a segment of the main trough over the Antarctic Peninsula. It is noted that there was an indication of weakly enhanced sDPR $\sim 1 \mathrm{~mm} \mathrm{~s}^{-1}$ observed by GPS receiver in O'Higgins at this time (not shown). This region is approximately magnetically conjugate with the eastern Canada province of $\mathrm{New}$ Brunswick, where weak scintillation (sDPR $\sim 2 \mathrm{~mm} \mathrm{~s}^{-1}$ ) mapped to the poleward edge of TEC trough by GPS receivers NRC1 (Ottawa) and FDRN (Fredericton).

At 08:00 UT, strong dawnward IMF $\left(B_{y}<0\right)$ resulted in a clear interhemispheric asymmetry of high-latitude convec- 


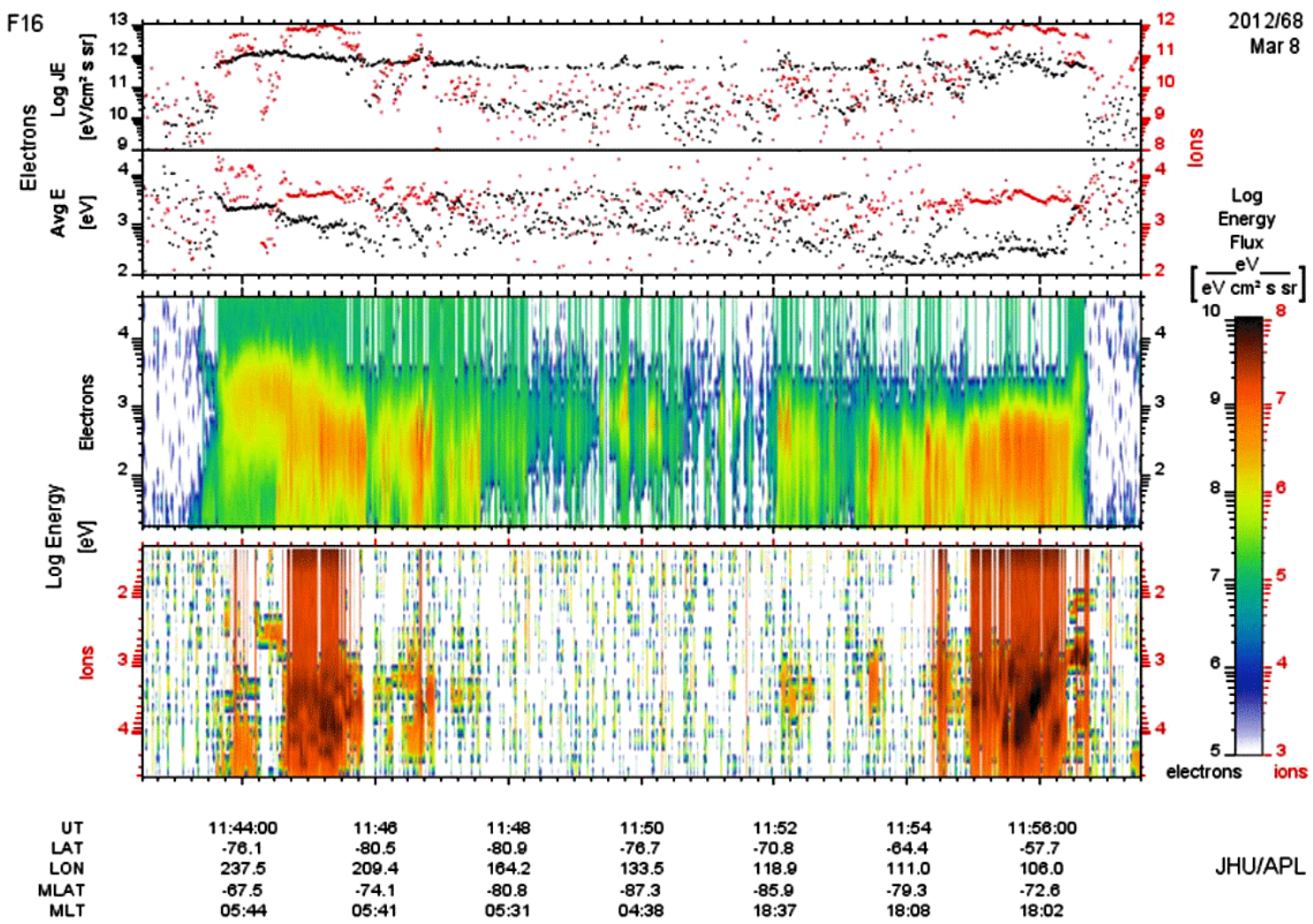

Figure 12. Precipitating particle fluxes observed by the F16 DMSP satellite during a pass over the southern auroral oval and polar cap.

tion and the orientation of the anti-sunward convection in the polar cap. Convection and TEC maps (Figs. 10 and 11) further illustrate the link between flow intensifications in the polar cap and the nightside auroral activity discussed in the companion paper (Prikryl et al., 2015a). In this case, the antisunward convection in the northern polar cap started to intensify after $\sim 07: 40 \mathrm{UT}$ (cross-polar cap potential, $\phi_{\mathrm{PC}} \approx$ $62 \mathrm{kV})$, and by the time it reached a maximum $\left(\phi_{\mathrm{PC}} \approx 76 \mathrm{kV}\right)$ at 08:00 UT (Fig. 10a), the convection in the exit region centered in the post-midnight sector strengthened and further intensified thereafter. High TEC values in the central polar cap indicate dense polar patches that were transported to the exit region. As the patches reach the auroral oval poleward boundary, they are known to be transformed into blobs (Crowley et al., 2000) and are the cause of strong scintillation (Jin et al., 2014). In the Northern Hemisphere, high TEC collocated with scintillation extended into the exit region in the post-midnight sector.

As shown in the companion paper, phase scintillation was collocated with strong transpolar arcs in the Northern Hemisphere during a period of northward $B_{z}$ on 8 March. The particle precipitation into transpolar arcs was observed during northern and southern high-latitude overpasses by DMSP satellites (http://sd-www.jhuapl.edu/Aurora/). Figure 12 shows DMSP F16 satellite particle data as it passed over the southern auroral oval (between $\sim 11: 43$ and
11:57 UT) crossing many transpolar arcs in the polar cap. The DMSP particle detectors observed electron precipitation fluxes with energies of $\sim 3 \mathrm{keV}$, indicating sun-aligned arcs in the polar cap (Newell et al., 2009). The SSUSI image scan (Fig. 13) showed numerous arcs particularly in the nightside polar cap that was not covered by GPS receivers at this time. Superposed on the image scans of aurora during the F16 pass are IPPs with enhanced scintillation. The mapping assumes a height of $110 \mathrm{~km}$ for both aurora and IPPs. Most of the IPPs were collocated with the dayside auroral oval, but IPPs in the polar cap indicate the scintillation was also caused by sunaligned arcs over McMurdo Station (just before 06:00 MLT at $80^{\circ} \mathrm{S}$ AACGM latitude) and at the south magnetic pole Dome $\mathrm{C}$ station.

\section{Summary and conclusions}

Phase scintillation was observed in the northern and southern high latitudes by arrays of GPS ionospheric scintillation and TEC monitors and geodetic-quality GPS receivers sampling at $1 \mathrm{~Hz}$ during the interval of 7-17 March 2012. The maps of scintillation occurrence as a function of altitudeadjusted corrected magnetic latitude and magnetic local time are compared for the Northern and Southern Hemisphere. Enhanced scintillation regions are identified with regions at 


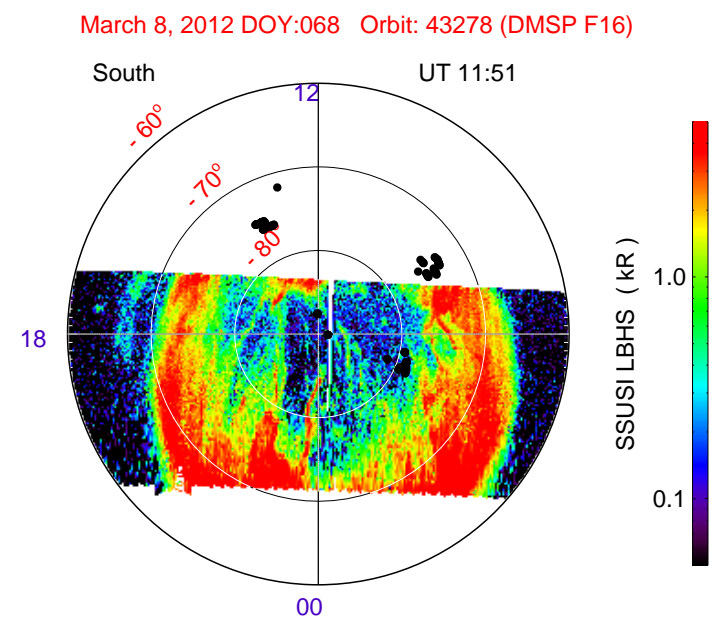

Figure 13. SSUSI (DMSP F16) auroral image scans mapped as a function of magnetic latitude and MLT. Superposed are IPPs (black dots) where scintillation $\sigma_{\Phi}$ or SDPR exceeded $0.1 \mathrm{rad}$ or $2 \mathrm{~mm} \mathrm{~s}^{-1}$.

high latitudes that are known as ionospheric signatures of the coupling between the solar wind and magnetosphere. In both hemispheres, enhanced phase scintillation was collocated with the ionospheric cusp, patches and sun-aligned arcs in the polar cap and nightside auroral oval. In the Northern Hemisphere, scintillation also mapped to subauroral polarization stream (SAPS) in the midnight sector and to the poleward edge of the storm-enhanced density (SED) on the dayside. Weak scintillation mapped to the poleward edge of TEC trough on the nightside. The comparison reveals interhemispheric similarities as well as asymmetries that are commonly manifested by the ionospheric convection at high latitudes observed by SuperDARN and supported by GPS TEC maps. The most prominent interhemispheric asymmetry is caused by the IMF dawn-dusk component that controls the location of the cusp and the orientation of the antisunward convection in the polar cap relative to the noonmidnight meridian. Consequently, the location and orientation of a band of scintillation that is collocated with a tongue of ionization that is fragmented into patches drawn through the cusp is controlled by the prevailing polarity of the IMF dawn-dusk component.

Acknowledgements. Infrastructure funding for CHAIN was provided by the Canada Foundation for Innovation and the New Brunswick Innovation Foundation. CHAIN and CGSM operation is conducted in collaboration with the Canadian Space Agency (CSA). The infrastructure for the GISTM at SANAE was provided by the South African National Antarctic Programme. The GISTM of southern auroral oval station Macquarie Island is operated by the Australian Bureau of Meteorology. Siena College gratefully acknowledges support from the National Science Foundation under award PLR-1248062. The Virginia Tech authors acknowledge the support through NSF awards AGS-0838219 and AGS-0946900. The authors acknowledge the use of SuperDARN data. SuperDARN is a collection of radars funded by national scientific funding agencies of Australia, Canada, China, France, Japan, South Africa, the United Kingdom and the United States of America. The DMSP particle detectors were designed by Dave Hardy of the Air Force Research Laboratory, and the data were obtained from Johns Hopkins University Applied Research Laboratory. The International GNSS Service (IGS) and its contributing organizations, including Denmark Technical University National Space Institute, are thanked for $1 \mathrm{~Hz}$ GPS data. This work was supported by the Public Safety Geosciences program of the Natural Resources Canada, Earth Sciences Sector (NRCan ESS contribution number 20140371).

The topical editor K. Hosokawa thanks N. Jakowski and one anonymous referee for help in evaluating this paper.

\section{References}

Akasofu, S.-I. and Tsurutani, B.: Unusual auroral features observed on January $10-11,1983$, their possible relationships to the interplanetary magnetic field, Geophys. Res. Lett., 11, 1086-1089, 1984.

Alfonsi, L., Spogli, L., De Franceschi, G., Romano, V., Aquino, M., Dodson, A., and Mitchell, C. N.: Bipolar climatology of GPS ionospheric scintillation at solar minimum, Radio Sci., 46, RS0D05, doi:10.1029/2010RS004571, 2011.

Baker, K. B. and Wing, S.: A new magnetic coordinate system for conjugate studies at high latitudes, J. Geophys. Res., 94, 91399143, 1989.

Basu S., Weber, E. J., Bullett, T. W., Keskinen, M. J., MacKenzie, E., Doherty, P., Sheehan, R., Kuenzler, H., Ning, P., and Bongiolatti, J.: Characteristics of plasma structuring in the cusp/cleft region at Svalbard, Radio Sci. 33, 1885-1899, doi:10.1029/98RS01597, 1998.

Chisham, G., Lester, M., Milan, S. E., Freeman, M. P., Bristow, W. A., Grocott, A., McWilliams, K. A., Ruohoniemi, J. M., Yeoman, T. K., Dyson, P. L., Greenwald, R. A., Kikuchi, T., Pinnock, M., Rash, J. P. S., Sato, N., Sofko, G. J., Villain J.-P., and Walker, A. D. M.: A decade of the Super Dual Auroral Radar Network (SuperDARN): Scientific achievements, new techniques and future directions, Survey Geophys., 28, 33-109, doi:10.1007/s10712007-9017-8, 2007.

Clausen, L. B. N., Baker, J. B. H., Ruohoniemi, J. M., Greenwald, R. A., Thomas, E. G., Shepherd, S. G., Talaat, E. R., Bristow, W. A., Zheng, Y., Coster, A. J., and Sazykin, S.: Large-scale observations of a subauroral polarization stream by midlatitude SuperDARN radars: Instantaneous longitudinal velocity variations, J. Geophys. Res., 117, A05306, doi:10.1029/2011JA017232, 2012.

Cowley, S. W. H.: Magnetospheric asymmetries associated with the Y-component of the IMF, Planet. Space Sci., 29, 79-96, 1981.

Cowley, S. W. H., Morelli, J. P., and Lockwood, M.: Dependence of convective flows and particle precipitation in the high latitude dayside ionosphere on the X-and Y-components of the interplanetary magnetic field, J. Geophys. Res., 96, 5557-5564, 1991.

Crowley, G., Ridley, A. J., Deinst, D., Wing, S., Knipp, D. J., Emery, B. A., Foster, F., Heelis, R., Hairston, M., and Reinisch, B. W.: Transformation of high-latitude ionospheric $\mathrm{F}$ region patches into blobs during the March 21, 1990, storm, J. Geophys. Res., 105, 5215-5230, doi:10.1029/1999JA900357, 2000. 
De Franceschi, G., Alfonsi, L., and Romano, V.: Isacco: an Italian project to monitor the high latitude ionosphere by means of GPS receivers. GPS Solutions, 10, 263-267, doi:10.1007/S10291006-0036-6, 2006.

DeWitt, R. N.: The occurrence of aurora in geomagnetically conjugate areas, J. Geophys. Res., 67, 1347-1352, doi:10.1029/JZ067i004p01347, 1962.

Dungey, J. W.: Interplanetary magnetic field and auroral zones, Phys. Rev. Lett., 6, 47-48, 1961.

Echer, E., Gonzalez, W. D., Tsurutani, B. T., and Gonzalez, A. L. C.: Interplanetary conditions causing intense geomagnetic storms (Dst $\leq-100 \mathrm{nT}$ ) during solar cycle 23 (1996-2006), J. Geophys. Res., 113, A05221, doi:10.1029/2007JA012744, 2008.

Feldstein, Y. I. and Starkov, G. V.: Dynamics of auroral belt and polar geomagnetic disturbances, Planet. Space Sci., 15, 209-230, 1967.

Foster, J. C.: Storm time plasma transport at middle and high latitudes, J. Geophys. Res., 98, 1675-1689, doi:10.1029/92JA02032, 1993.

Foster, J. C. and Burke, W. J.: SAPS: A new categorization for sub-auroral electric fields, Eos Trans. AGU, 83, 393-394, doi:10.1029/2002EO000289, 2002.

Foster, J. C., Coster, A. J., Erickson, P. J., Rich, F. J., and Sandel, B. R.: Stormtime observations of the flux of plasmaspheric ions to the dayside cusp/magnetopause, Geophys. Res. Lett., 31, L08809, doi:10.1029/2004GL020082, 2004.

Foster, J. C., Coster, A. J., Erickson, P. J., Holt, J. M., Lind, F. D., Rideout, W., McCready, M., van Eyken, A., Barnes, R. J., Greenwald, R. A., and Rich, F. J.: Multiradar observations of the polar tongue of ionization, J. Geophys. Res., 110, A09S31, doi:10.1029/2004JA010928, 2005.

Ghoddousi-Fard, R., Prikryl, P., and Lahaye, F.: GPS phase difference variation statistics: A comparison between phase scintillation index and proxy indices, Adv. Space Res., 52, 1397-1405, 2013.

Gonzales, W. D., Joselyn, J. A., Kamide, Y., Kroehl, H. W., Rostoker, G., Tsurutani, B. T., and Vasyliunas, V. M.: What is a geomagnetic storm?, J. Geophys. Res., 99, 5771-5792, 1994.

Greenwald, R. A., Baker, K. B., Dudeney, J. R., Pinnock, M., Jones, T. B., Thomas, E. C., Villain, J.-P., Cerrisier, J.-C., Senior, C., Hanuise, C., Hunsucker, R. D., Sofko, G., Koehler, J., Nielsen, E., Pellinen, R., Walker, A. D. M., Sato, N., and Yamagishi, H.: DARN/ SUPERDARN A global view of the dynamics of highlatitude convection, Space Sci. Rev., 71, 761-796, 1995.

Holzworth, R. H. and Meng, C.-I.: Mathematical Representation of the Auroral Oval, Geophys. Res. Lett., 2, 377-380, 1975.

Imber, S. M., Milan, S. E., and Lester, M.: The Heppner-Maynard Boundary measured by SuperDARN as a proxy for the latitude of the auroral oval, J. Geophys. Res. Space Physics, 118, 685-697, doi:10.1029/2012JA018222, 2013.

Jayachandran, P. T., Langley, R. B., MacDougall, J. W., Mushini, S. C., Pokhotelov, D., Hamza, A. M., Mann, I. R., Milling, D. K., Kale, Z. C., Chadwick, R., Kelly, T., Danskin, D. W., and Carrano, C. S.: Canadian High Arctic Ionospheric Network (CHAIN), Radio Sci., 44, RS0A03, doi:10.1029/2008RS004046, 2009.

Jiao, Y., Morton, Y. T., Taylor, S., and Pelgrum, W.: Characterization of high-latitude ionospheric scintillation of GPS signals, Radio Sci., 48, 698-708, doi:10.1002/2013RS005259, 2013.
Jin Y., Moen, J. I., and Miloch, W. J.: GPS scintillation effects associated with polar cap patches and substorm auroral activity: direct comparison, J. Space Weather Space Clim., 4, doi:10.1051/swsc/2014019, 2014.

King, J. H. and Papitashvili, N. E.: Solar wind spatial scales in and comparisons of hourly Wind and ACE plasma and magnetic field data, J. Geophys. Res., 110, A02104, doi:10.1029/2004JA010649, 2005.

Kinrade, J., Mitchell, C. N., Yin, P., Smith, N., Jarvis, M. J., Maxfield, D. J., Rose, M. C., Bust, G. S., and Weatherwax, A. T.: Ionospheric scintillation over Antarctica during the storm of 5-6 April 2010, J. Geophys. Res., 11, A05304, doi:10.1029/2011JA017073, 2012.

Kinrade, J., Mitchell, C. N., Smith, N. D., Ebihara, Y., Weatherwax, A. T., and Bust, G. S.: GPS phase scintillation associated with optical auroral emissions: First statistical results from the geographic South Pole, J. Geophys. Res. Space Physics, 118, 2490 2502, doi:10.1002/jgra.50214, 2013.

Kintner, P. M., Ledvina, B. M., and de Paula, E. R.: GPS and ionospheric scintillations, Space Weather, 5, S09003, doi:10.1029/2006SW000260, 2007.

Kozlovsky, A., Turunen, T., Koustov, A. and Parks, G.: IMF By effects in the magnetospheric convection on closed magnetic field lines, Geophys. Res. Lett., 30, doi:10.1029/2003GL018457, 2003.

Kunduri, B. S. R.: A study of interhemispheric magnetic conjugacy and large scale magnetosphere-ionosphere coupling using SuperDARN radars, PhD Thesis, Virginia Polytechnic Institute and State University, ISBN:9781303787812, 2013.

Kunduri, B. S. R., Baker, J. B. H., Ruohoniemi, J. M., Clausen, L. B. N., Grocott, A., Thomas, E. G., Freeman M. P., and Talaat, E. R.: An examination of inter-hemispheric conjugacy in a subauroral polarization stream, J. Geophys. Res., 117, A08225, doi:10.1029/2012JA017784, 2012.

Laundal, K. M. and Østgaard, N.: Asymmetric auroral intensities in the Earth's Northern and Southern hemispheres, Nature, 460, 491-493, doi:10.1038/nature08154, 2009.

Li, G., Ning, B., Ren, Z., and Hu, L.: Statistics of GPS ionospheric scintillation and irregularities over polar regions at solar minimum, GPS Solutions 14, 331-341, doi:10.1007/s10291009-0156-x, 2010.

Makarevich, R. A. and Bristow, W. A.: Fine structure of subauroral electric field and electron content, J. Geophys. Res. Space Physics, 119, 3789-3802, doi:10.1002/2014JA019821, 2014.

Milan, S. E., Lester, M., Cowley, S. W. H., and Brittnacher, M.: The convection and auroral response to a southward turning of the IMF: POLAR UVI, CUTLASS, and IMAGE signatures of transient magnetic flux transfer at the magnetopause, J. Geophys. Res., 105, 15741-15756, 2000.

Milan, S. E., Baddeley, L. J., Lester, M., and Sato, N.: A seasonal variation in the convection response to IMF orientation, Geophys. Res. Lett., 28, 471-474, 2001.

Newell, P. T., Liou, K., and Wilson, G. R.: Polar cap particle precipitation and aurora: Review and commentary, J. Atmos. Solar-Terr. Phys., 71, 199-215, 2009.

Ngwira, C. M., McKinnell, L., and Cilliers, P. J.: GPS phase scintillation observed over a high-latitude Antarctic station during solar minimum, J. Atmos. Sol. Terr. Phys., 72, 718-725, doi:10.1016/j.jastp.2010.03.014, 2010. 
Nishitani, N., Papitashvili, V., Ogawa, T., Sato, N., Yamagishi, H., Yukimatu, A. S., and Rich, F. J.: Interhemispheric asymmetry of the high latitude ionospheric convection on May 11-12, 1999, J. Geophys. Res., 108, 1184, doi:10.1029/2002JA009680, 2003.

Østgaard, N., Mende, S. B., Frey, H. U., Frank, L. A., and Sigwarth, J. B.: Observations of non-conjugate theta aurora, Geophys. Res. Lett., 30, 2125, doi:10.1029/2003GL017914, 2003.

Østgaard, N., Mende, S. B., Frey, H. U., Immel, T. J., Frank, L. A., Sigwarth, J. B., and Stubbs, T. J.: Interplanetary magnetic field control of the location of substorm onset and auroral features in the conjugate hemispheres, J. Geophys. Res., 109, A07204, doi:10.1029/2003JA010370, 2004.

Papitashvili, V. O., Christiansen, F., and Neubert, T.: A new model of field-aligned currents derived from high-precision satellite magnetic field data, Geophys. Res. Lett., 29, 1683, doi:10.1029/2001GL014207, 2002.

Paxton, L. J., Morrison, D., Zhang, Y., Kil, H., Wolven, B., Ogorzalek, B. S., Humm, D. C., and Meng, C.-I.: Validation of remote sensing products produced by the Special Sensor Ultraviolet Scanning Imager (SSUSI) - a far-UV imaging spectrograph on DMSP F16, Proc. SPIE, 4485, 338, 2002.

Prikryl, P., Jayachandran, P. T., Mushini, S. C., and Chadwick, R.: Climatology of GPS phase scintillation and HF radar backscatter for the high-latitude ionosphere under solar minimum conditions, Ann. Geophys., 29, 377-392, doi:10.5194/angeo-29-377-2011, 2011a.

Prikryl, P., Spogli, L., Jayachandran, P. T., Kinrade, J., Mitchell, C. N., Ning, B., Li, G., Cilliers, P. J., Terkildsen, M., Danskin, D. W., Spanswick, E., Donovan, E., Weatherwax, A. T., Bristow, W. A., Alfonsi, L., De Franceschi, G., Romano, V., Ngwira, C. M., and Opperman, B. D. L.: Interhemispheric comparison of GPS phase scintillation at high latitudes during the magnetic-cloudinduced geomagnetic storm of 5-7 April 2010, Ann. Geophys., 29, 2287-2304, doi:10.5194/angeo-29-2287-2011, 2011 b.

Prikryl, P., Zhang, Y., Ebihara, Y., Ghoddousi-Fard, R., Jayachandran, P. T., Kinrade, J., Mitchell, C. N., Weatherwax, A. T., Bust, G., Cilliers, P. J., Spogli, L., Alfonsi, L., De Franceschi, G., Romano, V., Ning, B., Li, G., Jarvis, M. J., Danskin, D. W., Spanswick, E., Donovan, E., and Terkildsen, M.: An interhemispheric comparison of GPS phase scintillation with auroral emission observed at South Pole and from DMSP satellite, Special Issue of Annals of Geophysics, 56, 2, R0216; doi:10.4401/ag-6227, 2013a.

Prikryl, P., Ghoddousi-Fard, R., Kunduri, B. S. R., Thomas, E. G., Coster, A. J., Jayachandran, P. T., Spanswick, E., and Danskin, D. W.: GPS phase scintillation and proxy index at high latitudes during a moderate geomagnetic storm, Ann. Geophys., 31, 805816, doi:10.5194/angeo-31-805-2013, 2013b.

Prikryl, P., Ghoddousi-Fard, R., Thomas, E. G., Ruohoniemi, J. M., Shepherd, S. G., Jayachandran, P. T., Danskin, D. W., Spanswick, E., Zhang, Y., Jiao, Y., and Morton, Y. T.: GPS phase scintillation at high latitudes during geomagnetic storms of 7-17 March 2012 - Part 1: The North American sector, Ann. Geophys., 33, 637656, doi:10.5194/angeo-33-637-2015, 2015a.
Prikryl, P., Ghoddousi-Fard, R., Ruohoniemi, J. M., and Thomas, E. G.: GPS phase scintillation at high latitudes during two geomagnetic storms, in: Auroral dynamics and space weather, edited by: Zhang, Y. and Paxton, L. J., AGU, Wiley Publ., accepted, 2015 b.

Rideout, W. and Coster, A.: Automated GPS processing for global total electron content data, GPS Solutions, 10, 219-228, 2006.

Ruohoniemi, J. M. and Baker, K. B.: Large-scale imaging of highlatitude convection with Super Dual Auroral Radar Network HF radar observations, J. Geophys. Res., 103, 20797-20811, doi:10.1029/98JA01288, 1998.

Sato, N., Nagaoka T., Hashimoto, K., and Saemundsson, T.: Conjugacy of isolated auroral arcs and nonconjugate auroral breakups, J. Geophys. Res., 103, 11641-11652, doi:10.1029/98JA00461, 1998.

Sato, N., Kadokura, A., Ebihara, Y., Deguchi, H., and Saemundsson, T.: Tracing geomagnetic conjugate points using exceptionally similar synchronous auroras, Geophys. Res. Lett., 32, L17109, doi:10.1029/2005GL023710, 2005.

Shepherd, S. G.: Altitude-adjusted corrected geomagnetic coordinates: Definition and functional approximations, J. Geophys Res. Space Physics, 119, doi:10.1002/2014JA020264, 2014.

Shepherd, S. G. and Ruohoniemi, J. M.: Electrostatic potential patterns in the high-latitude ionosphere constrained by SuperDARN measurements, J. Geophys. Res., 105, 23005-23014, doi:10.1029/2000JA000171, 2000.

Smith, A. M., Mitchell, C. N., Watson, R. J., Meggs, R. W., Kintner, P. M., Kauristie, K., and Honary, F.: GPS scintillation in the high arctic associated with an auroral arc, Space Weather, 6, S03D01, doi:10.1029/2007SW000349, 2008.

Spogli, L., Alfonsi, L., De Franceschi, G., Romano, V., Aquino, M. H. O., and Dodson, A.: Climatology of GPS ionospheric scintillations over high and mid-latitude European regions, Ann. Geophys., 27, 3429-3437, doi:10.5194/angeo-27-3429-2009, 2009.

Thomas, E. G., Baker, J. B. H., Ruohoniemi, J. M., Clausen, L. B. N., Coster, A. J., Foster, J. C., and Erickson, P. J.: Direct observations of the role of convection electric field in the formation of a polar tongue of ionization from storm enhanced density, J. Geophys. Res. Space Physics, 118, 11801189, doi:10.1002/jgra.50116, 2013.

Tsurutani, B. T., Jones, D. E., Lepping, R. P., Smith, E. J., and Sibeck, D. G.: The relationship between the IMF B $y$ and the distant tail (150-238 $\mathrm{R}_{e}$ ) lobe and plasma sheet $\mathrm{B}_{y}$ fields, Geophys. Res. Lett., 11, 1082-1085, doi:10.1029/GL011i010p01082, 1984.

Tsurutani, B. T., Echer, E., Shibata, K., Verkhoglyadova, O. P., Mannucci, A. J., Gonzalez, W. D., Kozyra, J. U., and Pätzold, M.: The interplanetary causes of geomagnetic activity during the 7-17 March 2012 interval: a CAWSES II overview, J. Space Weather Space Clim., 4, A02, doi:10.1051/swsc/2013056, 2014.

Zhang, Y. and Paxton, L. J.: An empirical Kp-dependent global auroral model based on TIMED/GUVI FUV data, J. Atmosph. Solar-Terrest. Phys., 70, 1231-1242, 2008. 